\title{
GRAMATICA LIMBII ROMÂNE ÎN VEȘMINTE NOI
}

ROMANIAN GRAMMAR'S NEW CLOTHES

\author{
Marcela CIORTEA \\ Universitatea 1 Decembrie 1918 din Alba Iulia / 1 Decembrie 1918 University of \\ Alba Iulia \\ e-mail: marcela.ciortea@uab.ro
}

\begin{abstract}
In 2005, The Romanian Academy published a new Romanian Language Grammar, four decades after the last edition of the previous Grammar. The event sparked a lot of controversy, even indignation, especially among those familiar with the old grammar and unwilling to embrace the interpretations of a new one. Only five years after this publication, a group of researchers separated themselves from the 2005 edition's authors and clustered around Professor Gabriela Pană Dindelegan, into a team of scholars who undertook the toilsome mission of aligning the Romanian grammar to the European research manner. The list of these works, purposefully set up in chronological order, offers on overall view of the researcher groups that have put an effort in this direction over the last ten years. The present paper addresses both the Romanian native speakers and those interested in the grammar of this language. It brings under scrutiny three segments: the pronominal clitics, verb voices and the prepositional complement.
\end{abstract}

Keywords: Romanian Grammar; Syntax, Dictionary; Old Romanian.

Iniţiată în anul 1949 și realizată în anul 1954 sub coordonarea lui D. Macrea, Gramatica limbii române, în două volume, cunoscută drept Gramatica Academiei (GA), a fost publicată în ediție revăzută și adăugită în anul 1963, sub coordonarea lui Alexandru Graur, a Mioarei Avram și a Laurei Vasiliu. Această gramatică, unanim acceptată drept gramatica oficială a limbii române, care avea să apară într-un nou tiraj în anul 1966, a patronat învățământul și cercetarea românească de profil vreme de patru decenii. Foarte bine sistematizată și foarte explicită, ea a deservit utilizatorii limbii române, fie ei nativi sau alolingvi, în tot acest interval, ba și după apariţia noii gramatici oficiale, în anul 2005.

Numai că, între timp, lucrurile s-au schimbat, iar ceea ce era suficient pentru nevoile unui public vorbitor cu granițe academice limitate de politica de stat a devenit insuficient în condițiile granițelor deschise după anul 1989. Pe de o parte, emigrarea masivă a plasat în mare dificultate elevii nevoiți să studieze în altă țară, unde s-au lovit de noțiuni necunoscute pentru ei, chiar dacă, fără să știe, le stăpâneau foarte bine în limba de origine; și aceasta, 
numai din cauză că, în școala românească li se spunea în alt fel decât în școala de adopție. În plus, numărul cercetătorilor români și al persoanelor doritoare să studieze în centre universitare din străinătate a crescut. Toate acestea au dus, implicit, la sporirea interesului străinilor față de limba română. Astfel, nevoia de aliniere la terminologia și la metodele de lucru internaționale a devenit inerentă. Prin urmare, s-au constituit echipe de lucru, în sarcina cărora a intrat punerea laolaltă a studiilor apărute între timp, răspândite prin reviste de specialitate sau chiar în lucrări de sine stătătoare, și redactarea unor lucrări coerente, prin care limba română să poată fi cercetată de pe poziții egale cu celelalte limbi, oriunde în lume.

Trecerea nu s-a făcut brusc, ci în etape, respectându-se, uneori tacit, alteori explicit, principiul concentric al învățării. Fiecare nouă lucrare din lista de mai jos își clădește conținuturile pe scheletul vechii gramatici, aducând completări acolo unde situaţia le impune. Iată lista lucrărilor de bază și a colectivelor de autori:

1966: Gramatica limbii române. Vol. I-II. Ediția a II-a revăzută și adăugită. Bucureşti: Editura Academiei. Coordonatori: Al. Graur, Mioara Avram, Laura Vasiliu. Autori: Finuța Asan, Mioara Avram, Elena Carabulea, Fulvia Ciobanu, Eugenia Contraș, Florica Ficşinescu, Mircea Mitran, Rodica Ocheșanu, Magdalena Popescu-Marin, I. Rizescu, Laura Vasiliu.

2005: Gramatica limbii române. Vol. I: Cuvântul. Vol. II: Enunțul. Academia Română, Institutul de Lingvistică „Iorgu Iordan - Al. Rosetti”. Bucureşti: Editura Academiei Române. Coordonator: Valeria Guţu Romalo. Autori: Raluca Brăescu, Elena Carabulea, Fulvia Ciobanu, Blanca Croitor Balaciu, Laurenția Dascălu Jinga, Andreea Dinică, Mihaela Gheorghe, Adriana Gorăscu, Valeria Guțu Romalo, Dana Manea, Margareta Manu Magda, Isabela Nedelcu, Gabriela Pană Dindelegan, Magdalena Popescu-Marin, Marina Rădulescu Sala, Camelia Stan, Domnița Tomescu, Andra Vasilescu, Ileana Vântu, Rodica Zafiu.

2010: Gramatica de bază a limbii române. București: Editura Univers Enciclopedic Gold. Coordonator: Gabriela Pană Dindelegan. Autori: Adina Dragomirescu, Isabela Nedelcu, Alexandru Nicolae, Gabriela Pană Dindelegan, Marina Rădulescu Sala, Rodica Zafiu.

2013: The Grammar of Romanian. Oxford University Press. Editor: Gabriela Pană Dindelegan. Autori: Raluca Brăescu, Blanca Croitor, Andreea Dinică, Adina Dragomirescu, Mihaela Gheorghe, Ana-Maria Iorga Mihail, Dana Manea, Margareta Manu Magda, Carmen Mârzea Vasile, Mona Moldoveanu Pologea, Isabela Nedelcu, Alexandru Nicolae, Irina Nicula, Dana Niculescu, Gabriela Pană Dindelegan, Camelia Stan, Andra Vasilescu, Rodica Zafiu.

2016: The Syntax of Old Romanian. Oxford University Press. Editor: Gabriela Pană

Dindelegan. Autori: Raluca Brăescu, Blanca Croitor, Andreea Dinică, Adina Dragomirescu, Mihaela Gheorghe, Martin Maiden, Dana Manea, Margareta Manu Magda, Carmen Mârzea Vasile, Isabela Nedelcu, Alexandru Nicolae, 
Irina Nicula Paraschiv, Dana Niculescu, Gabriela Pană Dindelegan, Camelia Stan, Emanuela Timotin, Oana Uță Bărbulescu, Andra Vasilescu, Rodica Zafiu.

2019: Sintaxa limbii române vechi. București: Editura Univers Enciclopedic Gold.

Editor: Gabriela Pană Dindelegan. Editor consultant: Martin Maiden.

Autori: Raluca Brăescu, Blanca Croitor, Andreea Dinică, Adina

Dragomirescu, Mihaela Gheorghe, Dana Manea, Margareta Manu Magda, Carmen Mârzea Vasile, Isabela Nedelcu, Alexandru Nicolae, Irina Nicula Paraschiv, Dana Niculescu, Gabriela Pană Dindelegan, Camelia Stan, Emanuela Timotin, Oana Uță Bărbulescu, Andra Vasilescu, Rodica Zafiu.

2019: Gramatica limbii române pentru gimnaziu. București: Editura Univers

Enciclopedic Gold. Coordonator: Gabriela Pană Dindelegan. Autori: Raluca Brăescu, Adina Dragomirescu, Isabela Nedelcu, Alexandru Nicolae, Gabriela Pană Dindelegan, Rodica Zafiu.

2020: Dicționar de interpretări gramaticale. Cuvinte mici, dificultăți mari. București: Editura Univers Enciclopedic Gold. Coordonator: Gabriela Pană Dindelegan. Autori: Raluca Brăescu, Adina Dragomirescu, Isabela Nedelcu, Alexandru Nicolae, Irina Nicula Paraschiv, Gabriela Pană Dindelegan, Rodica Zafiu.

Apariţia noii Gramatici a Academiei (GALR) în anul 2005 a stârnit o serie de controverse, și în rândul cercetătorilor, dar mai ales în rândul profesorilor deprinși în timp cu metoda tradițională de lucru, unii rezervați, alții chiar indignați în fața noii provocări. Gramatica de bază a limbii române (GBLR), publicată în anul 2010, avea să pună lucrurile pe jar, iar introducerea noii abordări în programele școlare, urmată de Gramatica limbii române pentru gimnaziu (GLRG), publicată în anul 2019, avea să aducă o serie de discuții în rândul celor de la catedră, mulți dintre ei ostili acestei schimbări de paradigmă, mulți deschiși la idee, însă reclamând nevoia unei formări. Să vedem, în esență, cum stau lucrurile, pe câteva cazuri concrete.

\section{Accentuat / neaccentuat vs. nonclitic / clitic}

Un motiv de nedumerire și chiar de nemulțumire, uneori, este de ce anume s-a renunțat, în programa și în manualele de gimnaziu, la denumirea neaccentuat pentru forma scurtă a pronumelui, în favoarea termenului clitic, aşa cum apare în descrierea de mai jos:

\begin{tabular}{|c|c|c|c|c|c|c|c|c|c|}
\hline \multirow{3}{*}{$\mathrm{az}$} & \multirow{3}{*}{ ormă } & \multicolumn{2}{|c|}{$\begin{array}{l}\text { Per } \\
\text { soana I }\end{array}$} & \multicolumn{2}{|c|}{$\begin{array}{l}\text { Perso } \\
\text { ana a II-a }\end{array}$} & \multicolumn{4}{|c|}{$\begin{array}{l}\text { Persoana } \\
\text { a III-a } \\
\end{array}$} \\
\hline & & \multirow[t]{2}{*}{ g. } & \multirow[t]{2}{*}{1.} & \multirow[t]{2}{*}{ g. } & \multirow[t]{2}{*}{1.} & \multicolumn{2}{|c|}{ ingular } & \multicolumn{2}{|c|}{ lural } \\
\hline & & & & & & $\cdot$ & . & $\cdot$ & . \\
\hline & & & & & & & & & \\
\hline
\end{tabular}




\begin{tabular}{|c|c|c|c|c|c|c|c|c|c|}
\hline . & & $u$ & \multirow[t]{2}{*}{$o i$} & $u$ & \multirow[t]{2}{*}{$o i$} & \multirow[t]{2}{*}{$l$} & \multirow[t]{2}{*}{$a$} & \multirow[t]{2}{*}{$i$} & \multirow[t]{2}{*}{ le } \\
\hline \multirow[t]{2}{*}{ c. } & ccentuată & ine & & ine & & & & & \\
\hline & litică $\quad$ c & $(\breve{a})$ & $e$ & $e$ & $(\breve{a})$ & i) $l$ & & i) $i$ & $e$ \\
\hline . & & & & & & \multirow[t]{2}{*}{$u i$} & \multirow[t]{2}{*}{$i$} & \multirow{2}{*}{\multicolumn{2}{|c|}{ or }} \\
\hline . & $\begin{array}{r}\mathrm{a} \\
\text { ccentuată }\end{array}$ & $i e$ & ouă & $i e$ & ouă & & & & \\
\hline & litică $\quad$ c & i) $m i$ & $e, n i$ & i) $t \underline{i} i$ & $(\breve{a}), v i$ & \multicolumn{2}{|c|}{ i) $i$} & \multicolumn{2}{|c|}{$e, l i$} \\
\hline . & & & & $u$ & $o i$ & & & & \\
\hline
\end{tabular}

FORMELE PRONUMELUI PERSONAL (GLRG 2019: 112)

Răspunsul se află, în parte, chiar în gramatica tradițională, care menționează limpede că formele accentuate ale pronumelui personal pot constitui singure propoziții, întrebări sau răspunsuri la întrebări (Cui i-ai dat cartea? Lui.), în timp ce formele neaccentuate nu pot alcătui singure propoziții și pot apărea fie nelegate, fie legate de cuvintele precedente, și atunci le numim enclitice, ori de cuvintele următoare, și atunci le numim proclitice (GA, 1966, I: 138-139). Iată, așadar, că termenul clitic nu ne este cu totul străin, câtă vreme 1-am întâlnit în două structuri care îl plasează, după caz, după sau înaintea unui cuvânt. Având, probabil, la origine, grecescul $\kappa \lambda i ́ v \omega$, care înseamnă a înclina, clitic desemnează cuvinte care nu pot primi în niciun caz accent și care fac obligatoriu corp comun cu alte cuvinte, pe accentul cărora se sprijină. Deci termenul clitic nu exclude termenul neaccentuat, ci îl folosește pentru a se defini. Dacă numim enclitică o unitate lingvistică nepurtătoare de accent, atașată unui cuvânt precedent, și, în mod similar, procliticăa, o unitate lingvistică neaccentuată atașată unui cuvânt următor, atunci o formă clitică este una care poate fi atât postpusă, cât și antepusă, și care manifestă anumite grade de dependență de niște cuvintesuport.

Acest grad de dependență se află în strânsă legătură cu atașarea la cuvântul suport. Termenul ataşare, atrage după sine opoziţia ataşat / neatașat, cunoscută din gramatica tradițională drept legat / nelegat. Legarea sau atașarea unul clitic la un cuvânt-suport este marcată în scris prin cratimă și se aplică exclusiv pentru cazurile acuzativ și dativ, singurele care dețin forme clitice (neaccentuate).

\section{Exemple:}

Pronume personal:

Formă clitică neatașată de acuzativ: Te vedeam la concert. (Complement direct) 

direct)

Formă clitică atașată de acuzativ: Te-am văzut la concert. (Complement

Formă clitică neatașată de dativ: Iți povestesc ceva. (Complement indirect)

Formă clitică ataşată de dativ: Ți-am povestit ceva. (Complement indirect)

Pronume reflexiv: direct)

Formă clitică neataşată de acuzativ: Se prezintă la concurs. (Complement direct)

Formă clitică atașată de acuzativ: $S$-a prezentat la concurs. (Complement

Formă clitică neatașată de dativ: Își croiește o rochie. (Complement indirect) Formă clitică atașată de dativ: Și-a croit o rochie. (Complement indirect)

Se cuvine să adăugăm aici toate lucrările din lista de mai sus țin cont de terminologia tradițională. Opoziția nonclitic / clitic a fost introdusă prudent și explicată pe larg, în strânsă legătură cu opoziția accentuat / neaccentuat. Datorită faptului că sunt lipsite de accent, formele clitice mai sunt numite și atone (GALR, 2005, I: 202), iar în calitatea lor de a fi ataşate sau neatașate mai sunt numite clitice conjuncte (legate) sau clitice libere (nelegate) (GALR, 2005, I: 202).

Ele nu trebuie confundate cu morfemele libere, care sunt niște mărci de recunoaștere, adică niște semne specifice unei categorii gramaticale. $\mathrm{Nu}$ sunt clitice, aşadar, ci sunt morfeme libere:

\section{Exemple:}

Articolul nehotărât: un om; niște oameni.

Auxiliarele verbale: $a m$ cântat; voi cânta.

Spre deosebire de morfemele mobile, care niciodată nu ocupă o poziție și o funcție sintactică, cliticele pronominale pot avea funcție sintactică proprie, primind restricții de formă (de caz) de la regent și ocupând o valență liberă a acestuia (GBLR, 2010: 12). Ce au, totuși, în comun, este faptul că nici cliticele, nici morfemele libere nu se pot constitui în centre de grup, deci nu-și pot atrage subordonați, ceea ce, în limbaj tradițional, înseamnă că nu pot fi termeni regenți pentru alte cuvinte.

\section{Diateză vs. construcții active / construcții pasive / construcții cu pronume reflexive}

O altă chestiune care a suscitat îndelungi discuții este eliminarea termenului diateză din programa școlară de gimnaziu.

Cuvântul diateză ișsi are originea în grecescul $\delta i \alpha \dot{\theta} \theta \sigma l \varsigma$, care înseamnă dispoziție, aranjare, ordonare. Gramatica tradițională ne spune că diateza este forma pe care o îmbracă verbul pentru a arăta în ce raport se află acțiunea pe care o exprimă cu autorul acestei acțiuni (GA, 1966, I: 208). 
Gramaticile actuale definesc acest autor în funcție de rolurile și de funcțiile sintactice care îi sunt atribuite (GALR, 2005, I: 480). Dacă îl numim agent (lat. agens) pe cel care face acțiunea și pacient (lat. patiens) pe cel care o suportă, vom vedea că aceste denumiri intervin asupra subiectului atunci când un enunț se reorganizează prin deplasarea interesului de la agent spre pacient sau chiar spre acțiune. Astfel, în enunțul Ion citește un roman., subiectul în nominativ este Ion și îl numim subiect-Agent, în timp ce, în enunțul Romanul este citit de Ion., subiectul în nominativ este romanul și îl numim subiect-Pacient. În mod similar, în enunțul Ion aleargă în parc., Ion este subiect-Agent, iar în enunțul Se aleargă în parc., prin lipsa oricărui subiect rezultă o structură impersonală.

Așadar, opozițiile de diateză se stabilesc într-o construcție de bază, activă, considerată nemarcată, și o construcție restructurată ierarhic, care poate fi pasivă sau impersonală (GBLR, 2010: 265). Restructurarea ierarhică presupune reorganizarea structurii sintactice a enunțului: complementul direct din construcția activă devine subiect în construcția pasivă, iar subiectul construcției active devine complement prepozițional (de agent) în construcția pasivă, în timp ce interesul comunicativ se orientează spre altă componentă a propoziției, deplasându-se de pe subiectul-Agent, Ion, pe subiectul-Pacient, romanul (Cf. GALR, 2005, I: 480-481).

Aceste două opoziții de diateză caracterizează clase diferite de verbe. În opoziția pasiv vs. activ intervin verbe tranzitive (ca în dubletul Romanul este citit de Ion. vs. Ion citește un roman.), iar în opoziția activ / personal vs. impersonal intervin verbe intranzitive (ca în dubletul Ion aleargă în parc. vs. Se aleargă în parc.). O observație interesantă este aceea că există clase întregi de verbe care nu participă la opozițiile de diateză: verbele și construcțiile intrinsec impersonale (trebuie, tună, plouă, îmi pare bine de ceva); verbele cu reflexiv inerent (se ramolește, se teme, se inserează); verbele copulative (este, devine, inseamnă), verbele cu subiect non-animat (apune, expiră, răsare). Pentru aceste verbe, categoria diatezei nu va fi menționată în analiză (GBLR, 2010: 265).

În ceea ce privește așa-numita diateză reflexivă, sesizăm eliminarea ei dintre valorile de diateză în gramaticile actuale. Deși o trata separat, gramatica tradițională exprima câteva rezerve asupra ei: verbele reflexive [...] se caracterizează prin aceea că se conjugă după conjugarea diatezei active, dar sunt întotdeauna însoțite de pronume reflexive în acuzativ sau în dativ. Dintre aceste verbe, puține au însă conținut specific, distinct de al diatezelor activă și pasivă, de aceea puține pot constitui o diateză aparte (GA, 1966, I: 209).

Gramaticile actuale nuanțează și explică foarte clar motivele pentru care s-a renunțat la diateza reflexivă. În primul rând, acele construcții cu reflexiv obligatoriu nu intră în opoziții de diateză, deoarece el nu pot apărea 
decât $\mathrm{cu}$ un clitic reflexiv exprimat: se îndrăgostește, dar nu și *îndrăgostește; își închipuie, dar nu și *închipuie. Apoi, construcțiile cu reflexiv propriu-zis (cu funcție sintactică de complement direct / indirect) nu implică o reorganizare ierarhică a structurii de bază, numărul și ierarhia complementelor rămânând același: Ion $\imath_{\mathrm{CD}}$ laudă vs. Ion $s e_{\mathrm{CD}}$ laudă ;on îti $i_{\mathrm{CI}}$ spune vs. Ion îșicI spune (GALR, 2005, I: 481-482; Cf. GBLR, 2010: 265).

Această demonstrație savantă, pe care am încercat să o sintetizăm în paragrafele de mai sus, nu constituie obiectul de interes al elevului de gimnaziu. Pentru acest segment de vârstă și de școlaritate este importantă sesizarea formelor verbale active, pasive, impersonale și cu pronume reflexiv. Dar pentru că aceste forme verbale fac parte din niște construcții sintactice mai ample, le vom numi construcții active, construcții pasive $c u$ a fi, construcții impersonale, construcții cu pronume reflexive (GALR, 2005, II: 131 ș. urm. Cf. GBLR, 2010: 266-268 și GLRG, 2019: 353 și urm.).

\section{Exemple:}

Construcție activă: Brutarul coace pâine.

Construcție pasivă marcată cu verbul $a$ fi: Pâinea este coaptă de brutar.

Construcție pasivă marcată prin pronume reflexiv: Pâinea se coace cu dragoste. școală.

Construcție impersonală marcată prin pronume reflexiv: Se merge pe jos la

Construcție cu clitic reflexiv complement direct: Se laudă singur.

Construcție cu clitic reflexiv complement indirect: Și-a cumpărat o carte. familia.

Construcție cu clitic reflexiv complement indirect posesiv: Şi-a ajutat

Construcție cu clitic reflexiv atribut: Tot mai citesc măiastra- $t$ i carte.

Construcție cu clitic reflexiv reciproc, complement direct: Se susțin între ei.

Construcție cu clitic reflexiv reciproc, complement indirect: Își dau binețe.

Construcție cu clitic reflexiv, component obligatoriu al verbului, în acuzativ: Se miră.

Construcție cu clitic reflexiv, component obligatoriu al verbului, în dativ: Imi imaginez.

\section{Complement indirect vs. complement prepozițional}

Separarea netă a complementului indirect în dativ de complementul prepozițional (considerat indirect în gramatica tradiţională) este, de asemenea, subiect de discuție. Pe lângă faptul că această deslușire ar putea fi susceptibilă de a crea confuzii, cel mai frecvent reproș care i se aduce este acela că prepoziția apare în conturarea mai multor funcții sintactice postverbale, motiv considerat de unii suficient pentru a le numi pe toate, în bloc, prepoziţionale. În realitate însă, departe de a crea confuzii, distingerea celor două tipuri de complemente lămurește și ajută atât la receptarea textului, cât și la crearea unor enunțuri corecte. 
Să vedem întâi definiţia complementului indirect în gramatica tradițională: Complementul indirect este partea de propoziție care determină un verb, o locuțiune verbală, un adverb, un adjectiv, o locuțiune adjectivală sau o interjecție, indicând, în general, obiectul căruia i se atribuie o acțiune, o însuşire sau o caracteristică (GA, 1966, II: 158). Sesizăm în însăşi definiția de bază segmentul căruia i se atribuie. Căruia, nu pe care, nu la care, nu de care etc. Prin urmare, cele mai frecvente roluri ale complementului indirect sunt cel de Destinatar și cel de Beneficiar al unei acțiuni (GALR, 2005, II: 403).

Acest tip de complement, păstrat în gramaticile actuale cu numele de complement indirect, acceptă dublarea printr-o formă clitică de pronume în același caz (GA, 1966, II: 167-168; Cf. GALR, 2005, II: 410 ș. urm.; GLRG, 2019: 293): Lui Ion îi pasă. $\mathrm{Nu}$ se poate spune același lucru despre complementul prepozițional, pe care imposibilitatea dublării, prin anticipare sau prin reluare, îl distinge atât de complementul direct, cât și de cel indirect.
Exemple:
Complement direct anticipat: $\hat{l} l$ văd pe Ion.
Complement direct reluat: Pe Ion $\hat{\imath} l$ văd.
Complement indirect anticipat: $\hat{I} i$ spun lui Ion.
Complement indirect reluat: Lui Ion $\hat{\imath} i$ spun.
Complement prepozițional: Pariez pe Ion.

Chiar dacă verbul a paria funcționează tranzitiv și numai în subsidiar, complementul lui direct este suma (o pariez), banii ( $i$ i pariez), absent în text, dar prezent în mintea receptorului: în niciun caz nu se va înțelege textul drept il pariez pe Ion. Segmentul pe Ion, nefiind substituibil cu o formă clitică de acuzativ ( pe el, $\hat{l} l$ ), nu poate fi interpretat complement direct. Iată, așadar, o distincție în plus, anume între complementul prepozițional și cel direct, care ajută la evitarea altor capcane similare, mai ales când se ivesc realizări propoziționale ale acestui tip de complement.
Exemple:
Complement direct: El îi supără pe vecini.
Complement prepozițional: El se supără pe vecini. (nu îi supără pe ei)
Dar și:
Completivă prepozițională: El își dă seama că e mințit.
Complement prepozițional: El își dă seama de minciună.

Locuțiunea $a$-și da seama impune o construcție prepozițională: $a-s ̦ i$ da seama de ceva, nu *a-și da seama ceva. În mod similar, cer construcție prepoziţională și alți regenți verbali: a se mira (de ceva), a se bucura (de ceva), a se gândi (la ceva), a se minuna (de/la ceva), a se lăsa (de ceva). 
Mai mult decât atât, cele două complemente, indirect și prepozițional, pot apărea în același enunț, fără să fie coordonate, lucru care dovedește că nu sunt părți de propoziție de același fel (GALR, 2005, II: 417; Cf. GBLR, 2010: 468; GLRG, 2019: 293).

\section{Exemple:}

$I_{\mathrm{CI}}$-am spus [despre tine $]_{\text {CPrep. }}$.

$\mathrm{Nu}-m i_{\text {CI }}$ pasă [de nimic $]_{\text {CPrep. }}$

$T i_{\mathrm{CI}} \mathrm{s}-\mathrm{a}$ urât $[\mathrm{cu} \text { binele }]_{\mathrm{CPrep}}$.

$V i_{\mathrm{CI}}$ s-a căşunat [pe el $]_{\mathrm{CPrep}}$.

$\hat{I} i_{\text {CI }}$ place $[\text { de el }]_{\text {CPrep }}$.

Spre deosebire de complementul indirect, prepoziționalul se poate exprima și prin forme verbale nepersonale, cu sau fără prepoziție:

Exemple:

Infinitiv cu prepoziție: A tăcea echivalează [cu a aproba $]_{\text {CPrep. }}$

Infinitiv fără prepoziție: Se teme [a spune $]_{\text {CPrep }}$ ceva.

Supin: M-am săturat [de citit $]_{\text {CPrep. }}$

Prin urmare, numim prepozițional complementul exprimat prin grup prepozițional cu verb la formă verbală nepersonală, ca în exemplele de mai sus, și pe cel exprimat prin grup prepozițional nominal, în genitiv (cu prepozițiile asupra, impotriva dușmanilor), în dativ (asupră-ne, împotrivămi) și în acuzativ (cu prepozițiile $c u, d e, l a$, din, în, între, pe, pentru, prin, rar spre, de la, peste. Un inventar al verbelor-centru cu cele mai frecvente prepoziții, în GBLR, 2010: 470-471). Dacă structura regentă este o construcție pasivă, iar prepoziționalul selectează prepoziția de (către), atunci îl vom numi complement de agent, iar dacă prevalează componenta circumstanțială, atunci el va fi analizat în clasa circumstanţialelor (GBLR, 2010: 470-471).

\section{Exemple:}

Complement prepozițional: Este detașat [de problemele $]_{\text {CPrep }}$ vieții.

Complement de agent: Este detașat [de director] $]_{\mathrm{CAg}}$ la alt departament.

Circumstanțial de cauză: Plânge [de ciudă] $]_{\text {CircCauza }}$.

Circumstanțial de scop: Plec [la cumpărături] $]_{\text {CircScop. }}$

Circumstanțial de relație: Ai crescut [în înălțime $]_{\text {CircRel. }}$

Circumstanţial de instrument: Scrie [cu stiloul $]_{\text {CircInstr. }}$

\section{În loc de încheiere}

Am încercat, în această prezentare, nu doar să lămurim unele aspecte legate de cliticele pronominale, de diateze și de complementul prepozițional, ci să arătăm publicului interesat, din țară și din străinătate, că are la dispoziție 
o bogată literatură de specialitate, pentru clarificarea oricărei probleme de gramatică românească. Demersul început în urmă cu șapte decenii de școala de la București, nuanțat și explicat pe îndelete, în tot acest interval, de specialiști din țară și din străinătate, a fost definitivat recent prin efortul conjugat al noii generații de cercetători bucureșteni, care au analizat rezultatele cercetărilor de profil de la toate centrele universitare din țară și chiar din străinătate.

Cercetarea privind limba română va merge de acum înainte pe acest făgaș, iar faptul că noțiunile elementare au fost introduse în programa școlară de gimnaziu din țară este, în mod evident, un pas înainte. Dacă, așa cum se intenționează, gramatica va fỉ introdusă și programa pentru clasele de liceu, acest lucru va fi în beneficiul studiului adecvat al limbii române în programele de licență, masterat și doctorat. Sintaxa limbii române vechi, publicată iniţial, în limba engleză, la Oxford (2016), uzează peste tot de noua terminologie. Dicționarul de interpretări gramaticale (2020), publicat la București, asemenea. Dacă de sintaxa limbii române vechi ar putea fi interesați doar specialiștii, cuvintele care stârnesc discuții datorită dificultăților de interpretare interesează pe toată lumea: substantive invariabile (învățătoare, nume), defective (argint, bucate), abstracte (dulceață, cinste); elemente funcționale legate de clasa numelui (al, lui); adverbe cu conversiune incompletă (vară, luni), modalizatoare de certitudine (musai, negreşit, sigur), de incertitudine (poate, parcă), evidențiale (chipurile, cică, darămite, pasămite); adjective invariabile (astfel, altfel), de tip afectiv (biet, drag, dulce); pronume relative (care, cine, ce, ceea ce), intensificatori (însuşi), cuantificatori (mulți, destui, nimic, nimeni), profraze (asta, ceea ce), dar și unele cu uz marginal (alde, atare, cutare, niscaiva); prepoziții cu încadrare nesigură (prepoziție sau conjuncție: de, până); conjuncții cu încadrare incertă (conjuncție sau adverb: deci, insăa, așadar), interjecții cu ambiguitate funcțională (au, hai, halal, iată, na, păi, uite, vai, zău) etc.

Profesorii nu trebuie să se teamă. Pentru explicarea noțiunilor la nivel gimnazial, un instrument de lucru foarte util este Gramatica limbii române pentru gimnaziu (2019), care propune, la finalul fiecărui capitol, seturi de exerciții. Pentru aprofundarea noțiunilor la nivel universitar, un instrument de lucru, de asemenea foarte util, este Gramatica de bază a limbii române (2010), însoțită de un caiet de exerciții, care propune, în egală măsură, și rezolvări. Un pic de interes, o doză minimă de curaj și un spirit de aventură ar netezi calea. 


\section{Referințe:}

Graur, A.; Avram, M., Vasiliu, L. (coord.) (1966). Gramatica limbii române / The Grammar of Romanian. Vol. I-II. Ediția a II-a revăzută și adăugită. Bucureşti: Editura Academiei.

Guţu Romalo, V. (coord.) (2005). Gramatica limbii române / The Grammar of Romanian. Vol. I: Cuvântul. Vol. II: Enunțul. Academia Română, Institutul de Lingvistică „Iorgu Iordan - Al. Rosetti”. Bucureşti: Editura Academiei Române.

Pană Dindelegan, G. (coord.) (2010). Gramatica de bază a limbii române / The Grammar of Romanian. București: Editura Univers Enciclopedic Gold.

Pană Dindelegan, G. (coord.) (2019). Gramatica limbii române pentru gimnaziu / Romanian Grammar for Secondary School. București: Editura Univers Enciclopedic Gold. 